\title{
LABEL TIME-TEMPERATURE INDICATOR MENGGUNAKAN CAMPURAN MINYAK NABATI UNTUK MEMONITOR MUTU MIKROBIOLOGI SUSU PASTEURISASI
}

\author{
[Time-Temperature Indicator Labels Made with Vegetable Oil Blends for Monitoring of the \\ Microbial Quality of Pasteurized Milk]
}

\author{
Anis Khairunnisa ${ }^{1)}$, Nugraha Edhi Suyatma ${ }^{1,2) \star}$, dan Dede Robiatul Adawiyah ${ }^{1,2)}$ \\ 1) Progam Studi Ilmu Pangan, Sekolah Pascasarjana, Institut Pertanian Bogor, Bogor \\ 2) Southeast Asian Food and Agricultural Science and Technology (SEAFAST) Center, Institut Pertanian Bogor, Bogor
}

Diterima 3 Juli 2018 / Disetujui 8 November 2018

\begin{abstract}
Pasteurized milk (PM) is a perishable product requiring storage at cold temperatures to maintain its shelf life. However, the temperature fluctuations during transportation, handling, and storage could affect the number of microbial counts of the product. A time-temperature indicator (TTI) can be used to monitor productconditions in real time, so consumers know the condition of the product during transportation and storage. This study aims to determine the ability of a mixed vegetable oil (VOB) as a TTI indicator and evaluate the validity of $T T I$ as an indicator of PM microbiological degradation. The VOB was produced from a mixture of palm oil (PO), canola oil (CA), and olive oil (OV) at ratio s of 50:40:10 (C1), 50:25:25 (C2), and $50: 10: 40 \%(\mathrm{~V} / \mathrm{V})(\mathrm{C} 3)$, with the addition of $0.25 \%(\mathrm{~m} / \mathrm{v})$ of red dye $(\mathrm{Cl} 16255)$. The VOBs were tested its for diffusion length, diffusion kinetics, and the accuracy of the prediction model of each indicator at isothermal temperatures. The VOB indicator can be applied to monitor the total growth of microbes in PM. The value of the activation energy (Ea) of each indicator was 34.289 (C1); 35,294 (C2) and 40,646 kJ/mol (C3), while the Ea value of the microbial spoilage in PM was $58,105 \mathrm{~kJ} / \mathrm{mol}$. The difference between the Ea PM value and each indicator was less than $25 \mathrm{~kJ} / \mathrm{mol}$. Indicating that the accuracy of the prediction model was good. At storage temperature of $29^{\circ} \mathrm{C}$, the critical limit for PM spoilage occurs after 24 hours of storage which correlated with the diffusion length indicator of 6.50 (C1), 6.25 (C2), and $5.5 \mathrm{~cm}$ (C3). Overall, the indicators ob served can be used to monitor the microbiological spoilage of $P M$, so that the actual quality of $P M$ before consumption can be estimated.
\end{abstract}

Keywords: activation energy, diffusion, indicator, TTI, Pasteurized milk

\begin{abstract}
ABSTRAK
Susu pasteurisasi (PM) merupakan salah satu jenis produk perishable, produk yang membutuhkan penyimpanan pada suhu dingin untuk meningkatkan umur simpannya. Fluktuasi suhu penyimpanan ketika proses transportasi, handling, dan penyimpanan akan berpengaruh terhadap peningkatan jumlah mikroba produk. Time-temperature indicator (TTI) dapat digunakan untuk memonitor kondisi produk secara realtime, sehingga konsumen mengetahui kondisi produk dalam transportasi dan penyimpanan. Penelitian ini bertujuan untuk mengetahui kemampuan m inyak nabati campuran (VOB) sebagai indikator TTI dan meng evaluasi validitas TTI sebagai indikator kerusakan mikrobiologis PM. VOB berasal dari campuran minyak sawit (PO), minyak kanola (CA), dan minyak zaitun (OV) pada rasio 50:40:10 (C1), 50:25:25 (C2), and $50: 10: 40 \%$ (v/v) (C3), dengan penambahan 0,25\% (b/v) pewarna merah (C.I. 16255). VOB diuji panjang difusi, kinetika difusi, dan akurasi model prediksi dari masing-masing indikator pada suhu isotermal. Indikator VOB dapat diaplikasikan untuk memonitor pertumbuhan total mikroba dari susu pasteurisasi. Nilai energi aktivasi (Ea) masing-masing indikator adalah 34,289 (C1); 35,294 (C2) dan 40,646 kJ/mol (C3), sementara nilai Ea kerusakan mikroba PMadalah sebesar $58,105 \mathrm{~kJ} / \mathrm{mol}$. Selisih nilai Ea PM dan masing masing indikator adalah kurang dari $25 \mathrm{~kJ} / \mathrm{mol}$. Selisih nilai Ea PM mengindikasikan akurasi model prediksi adalah baik. Pada suhu penyimpanan $29^{\circ} \mathrm{C}$, batas kritis kerusakan PM terjadi setelah 24 jam penyimpan an yang berkorelasi dengan indikator panjang difusi yaitu 6,50 (C1), 6,25 (C2), dan 5,5 cm (C3). Secara keseluruhan, indikator yang diamati dapat digunakan untuk memonitor kerusakan mikrobiologis PM, sehingga kualitas aktual PM sebelum dikonsumsi mampu untuk diperkirakan.
\end{abstract}

Kata kunci: difusi, energi aktivasi, indikator, susu pasteurisasi, TTI

*Penulis Korespondensi:

E-mail: nugrahaedhi@yahoo.com 


\section{PENDAHULUAN}

Time-Temperature Indicator (TTI) merupakan sebuah inovasi kemasan cerdas (Intelligence Packaging), berupa label yang mampu mengindikasikan perubahan yang terjadi pada suatu produk secara real-time berdasarkan perubahan suhu penyimpanan selama waktu tertentu. TTI berbasis difusi merupakan salah satu jenis $\mathrm{TI}$ yang telah diaplikasikan secara komersil. Pergerakan (difusi) indikator pada medium TTI mengindikasikan perubahan suhu penyimpanan dan/atau lamanya penyimpanan produk tersebut, yang secara tidak langsung akan menggambarkan penurunan mutu produk tersebut (Kim et al., 2015). Semakin lama waktu penyimpanan dan/ atau semakin tinggi suhu penyimpanan, maka akan semakin panjang difusi indikator tersebut. Panjangnya difusi indikator menggambarkan terjadinya penurunan mutu produk atau lamanya penyimpanan produk tersebut..

Titik kritis indikator TTI ialah kestabilannya pada suhu rendah. Aplikasi TTI umumnya untuk produk yang mudah rusak (perishable) serta memerlukan penyimpanan pada suhu rendah, untuk itu diperlukan indikator yang stabil pada suhu rendah. Salah satu produk yang dapat diaplikasikan untuk TTI ialah produk susu pasteurisasi (Pereira et al., 2015). Susu Pasteurisasi (PM) merupakan jenis produk perishable yang membutuhkan penyimpanan pada suhu refrigerasi agar umur simpannya meningkat. Proses pasteurisasi susu $\left(71-75^{\circ} \mathrm{C} ; 15\right.$ detik) hanya dapat membunuh $95 \%$ mikroba, dimana proses ini utamanya mampu membunuh bakteri patogen dan sebagian mikroba pembusuk, termasuk sebagian besar sel vegetatifnya (Arini, 2017). Produk hasil pasteurisasi harus selalu dikombinasikan dengan penyimpanan pada suhu rendah $\left( \pm 4^{\circ} \mathrm{C}\right)$ agar jenis mikroba yang bertahan tidak mampu untuk berkembang lebih cepat sehingga umur simpan susu pasteurisasi lebih panjang. Meskipun demikian, suhu penyimpanan dapat berubah selama proses transportasi, handling, dan penyimpanan. Fluktuasi suhu penyimpanan ini berpengaruh dalam meningkatkan jumlah mikroba produk. Untuk itu, monitoring kondisi suhu penyimpanan produk dalam bentuk TTI, khususnya terhadap produk perishable penting untuk dilakukan.

Indikator TTI harus memiliki titik leleh rendah dengan viskositas yang baik agar sensitif terhadap peningkatan suhu penyimpanan dan dapat lebih stabil pada kondisi suhu rendah. Terdapat beberapa metode yang diketahui mampu mengatasi masalah kestabilan minyak pada suhu rendah, misalnya hidrogenasi, interesterifikasi, fraksinasi, dan metode pencampuran secara fisik. Meskipun memiliki kemampuan yang sama dalam meningkatkan mutu minyak secara fisik, kimiawi, maupun sensoris, metode pencampuran minyak secara fisik (Oil blending method) merupakan salah satu metode yang tergolong aman tanpa menyebabkan terjadinya perubahan bentuk rantai asam lemak (Hashempour-Baltork, 2016).

Octaviasari (2014) menyebutkan bahwa penggunaan minyak berbasis kelapa sawit sebagai indikator memiliki panjang difusi yang khas dan baik diaplikasikan sebagai indikator label TTI berbasis difusi, namun rentang suhu aplikasinya terbatas pada suhu ruang saja. Hal tersebut dikarenakan rendahnya kestabilan minyak kelapa sawit pada suhu rendah. Kim et al. (2010) melaporkan bahwa pencampuran antara minyak sawit dengan minyak nabati bertitik leleh rendah, seperti minyak kedelai $\left(-16^{\circ} \mathrm{C}\right)$, minyak kanola $\left(-10^{\circ} \mathrm{C}\right)$, dan minyak zaitun $\left(-6^{\circ} \mathrm{C}\right)$ diketahui memiliki efek sinergis dalam menurunkan viskositas minyak campuran total. Hal ini yang melandasi penggunaan minyak nabati campuran (Vegetable oil blends atau VOB) sebagai indikator label TTI. Pemanfaatan VOB diharapkan menghasilkan indikator dengan rentang suhu aplikasi yang lebih luas dan memiliki nilai energi aktivasi yang sesuai standar serta memiliki sensitifitas yang baik terhadap perubahan suhu penyimpanan seiring dengan perubahan waktu penyimpanan.

Penelitian ini bertujuan untuk (1) mengetahui kemampuan minyak nabati campuran (VOB) sebagai indikator TTI dan (2) mengevaluasi kemampuannya dalam menentukan kerusakan mikrobiologis PM, dengan parameter observasi permodelan kinetika difusi indikator dan pertumbuhan total mikroba susu pasteurisasi, yang disimpan pada kondisi suhu isotermal.

\section{BAHAN DAN METODE}

\section{Bahan}

Terdapat tiga (3) jenis minyak nabati komersil yang digunakan yakni minyak sawit (PO) (PT. SMART Tbk, Jakarta, Indonesia) minyak kanola (Mazola) (CA), dan minyak zaitun (Ekstra virgin olive oil, Bertolli) (OV). Jenis pewarna indikator yang digunakan ialah pewarna merah larut lemak C.I. 16255 (Coloursea, PT. Centra Lautan Pewarna). Indikator diaplikasikan untuk mengevaluasi mutu mikrobiologis PM yang diperoleh dari Unit Pengolahan Susu PT. D-Farm Agriprima, Fakultas Peternakan IPB.

\section{Persiapan indikator}

Indikator dibuat menggunakan campuran minyak nabati PO:CA:OV dengan memiliki tiga variasi rasio pencampuran yang berbeda yakni 50:40:10 (C1); 50:25:25 (C2), dan 50:10:40\% (v/v) (C3). Campuran dipanaskan hingga mencapai suhu $40^{\circ} \mathrm{C}$ menggunakan pengaduk magnetik selama 10 menit. Sampel indikator kemudian ditambahkan 0,25\% (b/v) pewarna merah C.I. 16255 (Modifikasi Roiaini et al., 2015). 


\section{Pengukuran panjang difusi indikator}

Pengukuran panjang difusi indikator didasarkan atas panjang difusi indikator pada medium kertas foto waterproof (Waterproof professional glossy photo paper, Merk Printech $\AA$ ) berukuran $10 \mathrm{~cm} \times 2,0$ $\mathrm{cm} \times 0,01 \mathrm{~cm}$. Medium direndam dalam $2 \mathrm{~mL}$ untuk setiap jenis indikator. Setiap wadah berisi medium dan indikator ini kemudian disimpan dalam inkubator (Leec compact incubator dan B6200 incubator Heraeus Instrument Kelvitron $\AA$ ) dan refrigerator (LG GN-B185SQBB) pada lima suhu isotermal, sebagai representasi kemungkinan kondisi lingkungan penyimpanan yakni pada suhu $4,18,29,37$, dan $40^{\circ} \mathrm{C}$ selama 30 jam. Pengukuran jarak difusi dilakukan setiap jam untuk lima jam pertama lalu dilanjutkan setelah 20 jam berikutnya hingga 30 jam terlewati (modifikasi dari Kim et al., 2015). Pengamatan pada setiap suhu penyimpanan diulangi sebanyak tiga kali.

\section{Perhitungan energi aktivasi indikator}

Hasil pengukuran panjang difusi indikator berupa data panjang difusi indikator $(x, \mathrm{~cm})$ dan lama penyimpanan ( $\mathrm{t}$, jam). Kedua nilai ini digunakan untuk menentukan nilai koefisien difusi $\left(\mathrm{D} \mathrm{cm}^{2} / \mathrm{jam}\right)$ (Persamaan 1, Tabel 1) yang merupakan bagian dari persamaan hukum Fick kedua (Fick's second law). Nilai $D$ setiap jenis indikator diubah dalam bentuk liniernya (In D) kemudian di-plotting sebagai sumbu $Y$, sedangkan sumbu $X$ ialah suhu penyimpanan ( $T$, dalam satuan Kelvin). Hasil plotting data berupa nilai regresi $\left(R^{2}\right)$ dan persamaan garis $(Y=a+b x)$. Persamaan garis yang diperoleh digunakan untuk menentukan nilai energi aktivasi (Ea, $\mathrm{kJ} / \mathrm{mol}$ ) dan menentukan model difusi setiap jenis indikator. Nilai tetapan gas ideal $(\mathrm{R})$ diketahui sebesar $8.314 \mathrm{~J} / \mathrm{mol}$.K. Penentuan model kinetika reaksi difusi ini menggunakan persamaan Arrhenius yang dimodifikasi (Persamaan 3, Tabel 1) (Kim et al., 2015).

\section{Perhitungan total mikroba dan energi aktivasi PM}

Analisis total mikroba PM dilakukan dengan metode tuang hitungan cawan, menggunakan media agar padat PCA (Plate Count Agar, MERCK, Jerman) yang disimpan di suhu 4,29 dan $40^{\circ} \mathrm{C}$ pada jam ke $0 ; 2 ; 4 ; 6 ; 8 ; 10 ; 24 ; 26 ; 28$; dan 30 (Modifikasi dari Kim et al., 2015). Pengujian total mikroba (N, CFU/mL) dilakukan sebagai dua kali ulangan pengukuran. Perhitungan total mikroba menggunakan Persamaan 4 , dengan $\mathrm{N}=$ total mikroba (CFU $\mathrm{mL}^{-1}$ ); $\Sigma \mathrm{C}=$ jumlah koloni yang dihitung; $\mathrm{n}_{1}$ jumlah cawan pada pengenceran $1 ; \mathrm{n}_{2}=$ jumlah cawan pada pengenceran 2; $d=$ pengenceran terendah.

$N(C F U / m L)=\frac{\sum c}{\left(1 \times n_{1}\right)+\left(0,1 \times n_{2}\right)+d}$

Penentuan nilai Ea kerusakan mutu mikrobiologis PM dilakukan berdasarkan persamaan orde satu, dengan menghubungkan antara waktu ( $t$, jam) dan In $\left(\mathrm{N} / \mathrm{N}_{0}\right) \quad(\mathrm{CFU} / \mathrm{mL})$. Persamaan garis ini menunjukkan persamaan Arrhenius (Persamaan 2, Tabel 1) sehingga nilai Ea dapat diketahui. Nilai Ea kerusakan mikroba PM juga digunakan untuk menduga umur simpan PM (Persamaan 5, Tabel 1).

\section{Analisis data}

Analisis data sederhana, penentuan standar deviasi (SD), dan pembuatan grafik diolah menggunakan Microsoft Excel 2013 (Microsoft Office Co. Inc.). Analisis statistik lanjutan seperti analisis regresi dan analisis sidik ragam (ANOVA) menggunakan program statistic SPSS 20.0. Jika terdapat perlakuan yang berpengaruh nyata maka pengujian dilanjutkan dengan analisis lanjutan menggunakan metode analisis Duncan Multiple Range Test (DMRT) dengan taraf signifikansi $5 \%$. Data dianggap berbeda secara signifikan apabila $P<0,05$.

\section{HASIL DAN PEMBAHASAN}

\section{Nilai koefisien difusi (D)}

Analisis sidik ragam menunjukkan bahwa suhu penyimpanan dan jenis indikator berpengaruh secara signifikan $(P<0,05)$ terhadap koefisien difusi indikator. Gambar 1 menampilkan nilai koefisien difusi tiga jenis indikator pada kondisi suhu isotermal (4, $18,29,37$, dan $40^{\circ} \mathrm{C}$ ). Setiawan (2012) menjelaskan bahwa nilai koefisien difusi merupakan fungsi eksponensial dari suhu. Semakin tinggi suhu penyimpanan, maka semakin cepat laju difusi dan semakin besar nilai koefisien difusinya.

Tabel 1. Persamaan yang digunakan menentukan energi aktivasi indikator dan PM

\begin{tabular}{|c|c|c|c|}
\hline & Nama Persamaan & Persamaan & Referensi \\
\hline (Persamaan 1) & Koefisien difusi & $\mathrm{x}^{2}\left(\mathrm{~cm}^{2}\right)=2 \mathrm{Dt}$ & Setiawan (2015) \\
\hline & & $\mathrm{D}\left(\mathrm{cm}^{2} / \mathrm{jam}\right)=\frac{\mathrm{x}^{2}}{2 \mathrm{t}}$ & \\
\hline (Persamaan 2) & Arrhenius & $\operatorname{Ln} k=-\left(\frac{E a}{R}\right) \frac{1}{T}+\ln k_{0}$ & \\
\hline (Persamaan 3) & Arrhenius yang dimodifikasi & $\operatorname{Ln} D=-\left(\frac{E a}{D}\right) \frac{1}{\tau}+\ln D_{0}$ & Kim et al. (2015) \\
\hline (Persamaan 5) & Umur simpan & $t_{s}(\mathrm{jam})=\frac{\left[\ln \left(\mathrm{N}_{0} / \mathrm{N}_{\mathrm{s}}\right]\right.}{\mathrm{k}}$ & \\
\hline
\end{tabular}


Hal ini sesuai dengan hukum Arrhenius yang menyatakan bahwa kenaikan konstanta laju reaksi sebanding dengan kenaikan suhu lingkungan (Zhou et al., 2015).

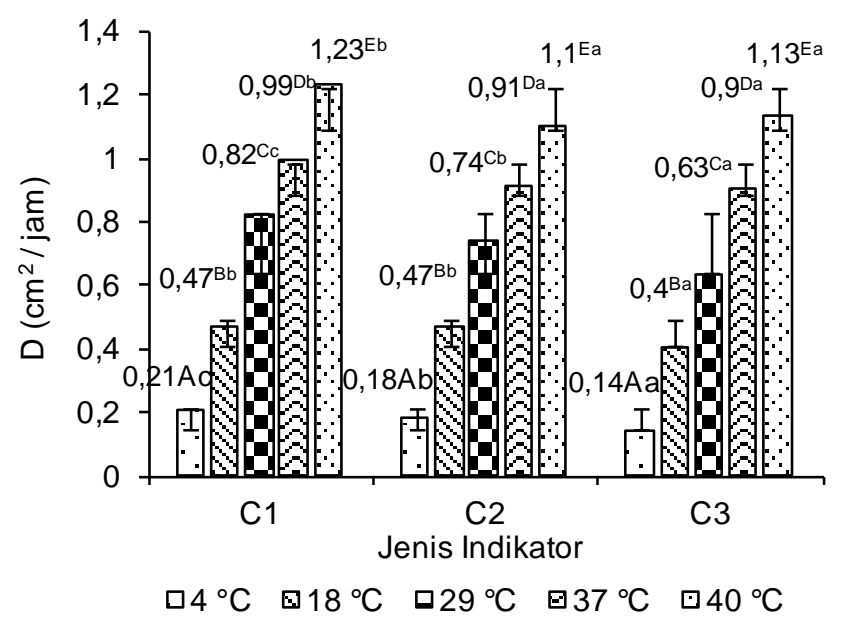

Keterangan: Perbedaan huruf (kapital: perbedaan suhu; normal: perbedaan jenis indikator) menunjukkan adanya perbedaan yang nyata dari perlakuan pada taraf nyata $\alpha=0,05$

Gambar 1. Koefisien difusi indikator (D) pada kondisi suhu isotermal

Rosyidah (2005) menyatakan bahwa selain suhu penyimpanan, koefisien difusi dipengaruhi pula oleh panjang difusi dan viskositas indikator sebagai difusan. Penurunan viskositas indikator membuat laju difusi meningkat. Ketika laju difusi indikator meningkat, maka pada batasan tertentu, panjang difusi dan nilai koefisien difusinya pun semakin meningkat seiring dengan meningkatnya suhu penyimpanan.

Nilai koefisien difusi indikator digunakan untuk menentukan nilai energi aktivasi masing-masing indikator $(\mathrm{Ea}, \mathrm{kJ} / \mathrm{mol})$. Agar diperoleh nilai $\mathrm{Ea}$, nilai koefisien difusi harus dikonversi dalam bentuk liniernya menjadi bentuk In $\mathrm{D}$, kemudian dilakukan plotting antara nilai In D setiap jenis indikator (sumbu y) terhadap nilai $1 / T$ (sumbu $\mathrm{X}$ ). Hasil plotting 1/T dan In D ditampilkan pada Gambar 2. Berdasarkan Gambar 2, terlihat bahwa semakin tinggi suhu penyimpanan maka semakin rendah nilai In $D$, sementara nilai $D$ meningkat. Hubungan parameter $1 / T$ dan In $\mathrm{D}$ ini menghasilkan persamaan garis linier berupa persamaan Arrhenius, yang nilai slopenya digunakan untuk menentukan nilai Ea masing-masing jenis indikator (dengan nilai $R$ sebesar $8,314 \mathrm{~J} / \mathrm{mol} \cdot \mathrm{K}$ ).

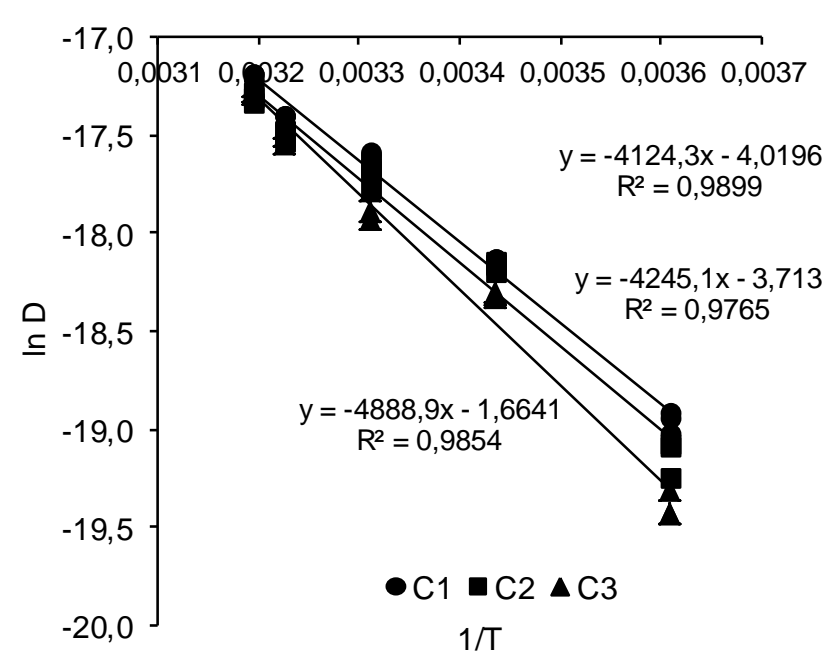

Gambar 2. Plot $1 /$ T dan In D indikator

\section{Energi aktivasi indikator (Ea)}

Nilai Ea menunjukkan besarnya jumlah energi awal yang dibutuhkan untuk memulai reaksi difusi indikator pada medium. Gambar 2 dan Tabel 2 menunjukkan bahwa penurunan nilai In $D$ berhubungan dengan peningkatan nilai $D$ dan penurunan nilai Ea indikator. Penurunan nilai In $\mathrm{D}$ atau peningkatan nilai $D$ selaras dengan peningkatan laju difusi. Peningkatan laju difusi dan koefisien difusi berkorelasi signifikan dengan peningkatan suhu penyimpanan, begitu pula nilai Ea.

Hasil perhitungan nilai Ea masing-masing indikator dapat dilihat pada Tabel 2. Secara keseluruhan, nilai Ea indikator ialah $34,289 \mathrm{~kJ} / \mathrm{mol}$ (C1), 35,294 kJ/mol (C2), dan 40,646 kJ/mol (C3), sementara nilai Ea salah satu jenis indikator TTI berbasis difusi komersil ialah $33-50 \mathrm{~kJ} / \mathrm{mol}$ (Pocas et al., 2008). Hal ini menunjukkan bahwa ketiga jenis indikator memiliki nilai Ea yang sesuai dengan standar nilai Ea komersil. Nilai Ea indikator yang diperoleh bernilai positif. Positifnya nilai Ea diartikan sebagai terjadinya kesesuaian antara indikator dengan sifat mediumnya, sehingga indikator membutuhkan sejumlah energi minimum awal untuk melakukan proses difusi pada medium (Octaviasari, 2014).

Wang et al. (2015) menjelaskan bahwa nilai Ea merefleksikan laju reaksi (laju difusi) yang dipengaruhi oleh suhu. Ketika nilai Ea meningkat maka pengaruh suhu terhadap laju reaksi semakin signifikan dan indikator semakin sensitif terhadap perubahan suhu.

Tabel 2. Nilai Ea dan prediksi model difusi indikator

\begin{tabular}{ccccc}
\hline Jenis Indikator & Persamaan Regresi & Ea $(\mathrm{kJ} / \mathrm{mol})$ & $\mathrm{R}^{<}$ & $\left(\right.$EapM - Ea $\left.a_{\text {indikator }}\right)(\mathrm{kJ} / \mathrm{mol})$ \\
\hline C1 & Ln D $=-4124,3 \frac{1}{\mathrm{~T}}-4,0196$ & 34,289 & 0,9899 & 23,816 \\
C2 & Ln D $=-4245,1 \frac{1}{\mathrm{~T}}-3,713$ & 35,294 & 0,9765 & 22,811 \\
C3 & Ln D $=-4888,9 \frac{1}{\mathrm{~T}}-1,6641$ & 40,646 & 0,9865 & 17,459 \\
\hline
\end{tabular}


Berdasarkan pernyataan ini jika diurutkan maka indikator $\mathrm{C} 1$ diprediksi memiliki sensitifitas yang tidak lebih baik dibanding indikator C2 dan C3, sementara indikator C3 memiliki sensitifitas yang baik terhadap perubahan suhu penyimpanan dibanding indikator lainnya.

\section{Aplikasi indikator pada PM}

Hasil perhitungan menunjukkan bahwa nilai $\mathrm{Ea}$ kerusakan PM karena pertumbuhan mikroba yang disimpan pada suhu 4,29 , dan $40^{\circ} \mathrm{C}$ ialah sebesar $58,105 \mathrm{~kJ} / \mathrm{mol}$. Nilai Ea kerusakan mikroba PM berguna untuk melihat reabilitas pengaplikasian indikator pada PM, melalui selisih antara nilai Ea produk dan indikator $\left(\mathrm{Ea}_{(f \circ o d)}-\mathrm{Ea}_{(\mathrm{TI})}\right)$ (Suppakul et al., 2017). Hasil perhitungan selisih kedua jenis nilai Ea ini dapat dilihat pada Tabel 2. Berdasarkan perhitungan, diketahui bahwa selisih nilai Ea PM dan indikator kurang dari $25 \mathrm{~kJ} / \mathrm{mol}$. Hal ini menunjukkan bahwa reabilitas indikator baik sehingga indikator dapat diaplikasikan untuk mengindikasikan kerusakan mikroba PM (Giannoglou et al., 2014).

Jumlah cemaran total mikroba awal PM ialah $1,0 \times 10^{1} \mathrm{CFU} / \mathrm{mL}$. Batas aman jumlah cemaran total mikroba PM menurut SNI (Standar Nasional Indone-

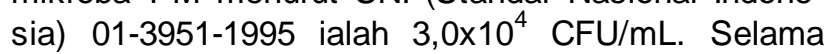
penyimpanan 30 jam, pertumbuhan total mikroba PM diketahui berada pada fase logaritmik. Budiyono (2009) menjelaskan bahwa hasil perhitungan jumlah total mikroba awal selama fase logaritmik berguna untuk menentukan waktu ketika jumlah mikroba telah mencapai batas kritis, melalui analisis regresi linier dan persamaan Arrhenius.

Perhitungan umur simpan (Tabel 3) menunjukkan bahwa prediksi waktu yang diperlukan PM untuk mencapai batas kritis pertumbuhan mikroba ialah 25 jam jika disimpan pada suhu $29^{\circ} \mathrm{C}$. Suhu $29^{\circ} \mathrm{C}$ dipilih sebagai salah satu contoh suhu penyimpanan ekstrem untuk susu pasteurisasi. Peningkatan suhu penyimpanan dapat mempercepat kerusakan sehingga umur simpan susu pasteurisasi semakin pendek. Hasil prediksi ini berfungsi untuk menentukan endpoint indikator.

Endpoint merupakan batas panjang difusi yang menunjukkan telah terjadinya penurunan kualitas hingga mencapai batas amannya. Endpoint indikator diperlukan untuk mengetahui kemampuan indikator dalam mengindikasikan kerusakan PM karena pertumbuhan mikroba (Suppakul et al., 2017).

Berdasarkan Gambar 3 diketahui bahwa endpoint indikator ialah pada panjang difusi (terukur) $6,50 \mathrm{~cm}$ (C1), 6,25 cm (C2), dan 5,50 cm (C3). Indikator C3 diketahui memiliki panjang endpoint teren- dah, sementara indikator C1 memiliki panjang endpoint terpanjang dibanding dua jenis indikator lain.
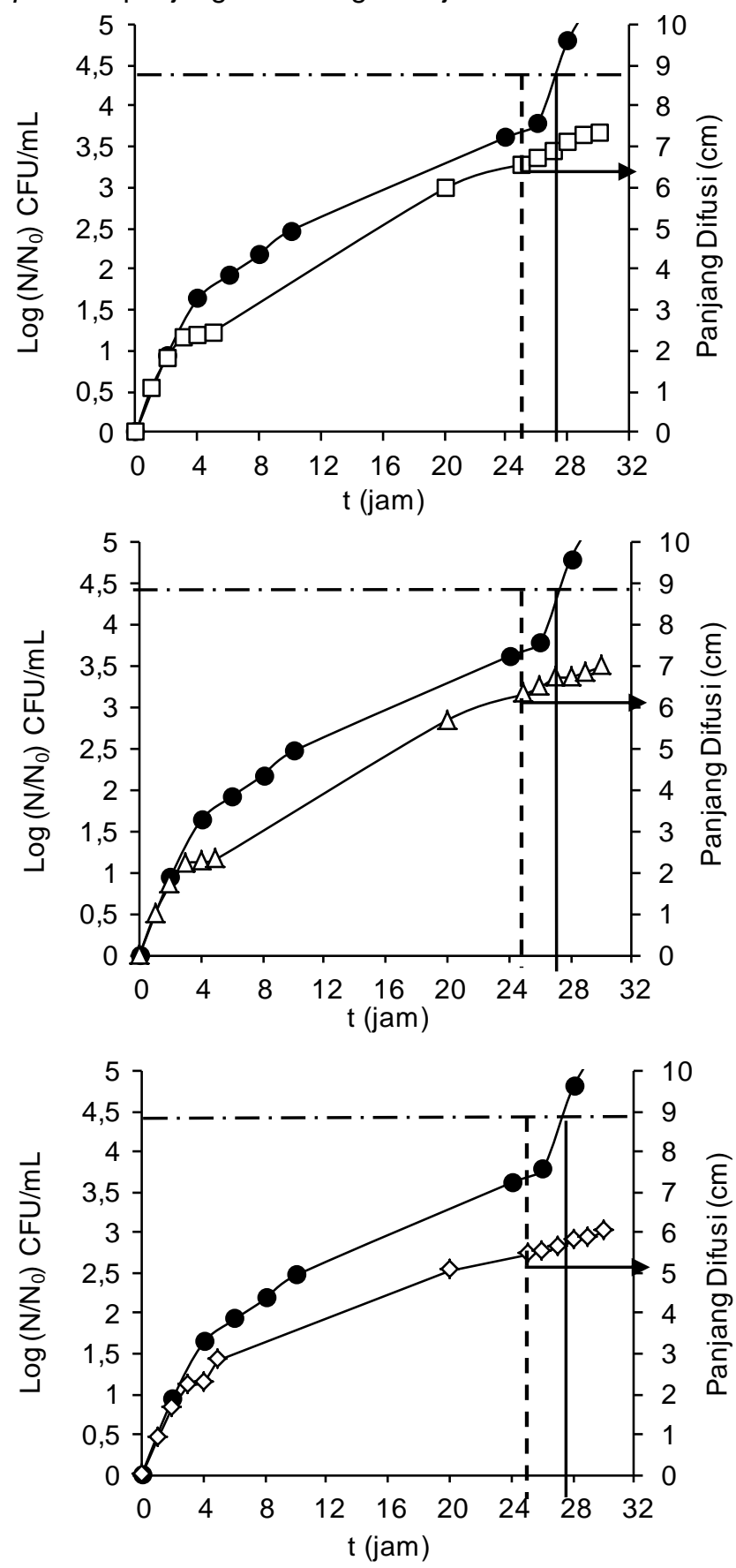

Keterangan:- - = pertumbuhan total mikroba; $-\square-=$ jarak difusi C1 (aktual); $-\backsim=$ jarak difusi C2 (aktual); $\checkmark-=$ jarak difusi C3 (aktual); $-=$ ts terukur; ---. $=$ ts prediksi

Gambar 3. Penentuan umur simpan PM secara prediksi dan aktual serta penentuan endpoint indikator pada suhu $29^{\circ} \mathrm{C}$

Tabel 3. Prediksi umur simpan (ts) PM yang disimpan pada suhu $29^{\circ} \mathrm{C}$

\begin{tabular}{ccccccc}
\hline $\mathrm{T}\left({ }^{\circ} \mathrm{C}\right)$ & $\mathrm{N}_{0}(\mathrm{CFU} / \mathrm{mL})$ & $\mathrm{Ns}(\mathrm{CFU} / \mathrm{mL})$ & $\operatorname{Ln}\left(\mathrm{N}_{0} / \mathrm{N}_{\mathrm{s}}\right)$ & $\mathrm{k}$ & ts (jam) & ts (hari) \\
\hline 29 & $1 \times 10^{\prime}$ & $3 \times 10^{4}$ & $-8,006$ & 0,321 & 25 & 1 \\
\hline
\end{tabular}


Gambar 3 juga memperlihatkan bahwa pada kisaran waktu 27-28 jam, pertumbuhan total mikroba PM secara aktual yang disimpan pada suhu $29^{\circ} \mathrm{C}$ sudah melebihi batas aman cemaran menurut SNI. Prediksi umur simpan PM menggunakan persamaan Arrhenius pada suhu $29^{\circ} \mathrm{C}$ ialah 25 jam (Tabel 3). Hal ini menunjukkan adanya under prediction (UP) karena hasil prediksi umur simpan lebih cepat waktunya dibanding umur simpan aktual. Suppakul et al. (2017) menyatakan bahwa under prediction dapat meningkatkan kewaspadaan terhadap kerusakan produk sebelum kerusakan mencapai batas maksimalnya.

\section{KESIMPULAN}

Pencampuran minyak sawit dengan minyak kanola dan zaitun dengan beberapa variasi rasio pencampuran mampu menurunkan viskositas minyak campuran akhir (indikator). Semakin menurunnya viskositas indikator maka laju difusi dan koefisien difusi semakin besar, sementara nilai energi aktivasinya mengalami penurunan. Indikator TTI berbasis difusi yang dikembangkan ini mampu menghasilkan nilai Ea yang sesuai dengan standar indikator TTI berbasis komersil. Nilai Ea indikator yang dihasilkan juga memiliki sensitifitas yang baik terhadap perubahan suhu penyimpanan selama waktu penyimpanan tertentu, terlihat dari adanya pengaruh yang signifikan dari perbedaan suhu penyimpanan terhadap nilai koefisien difusi indikator $(P<0,05)$. Aplikasinya pada suhu penyimpanan $29^{\circ} \mathrm{C}$ menunjukkan bahwa indikator yang dikembangkan ini mampu memprediksi kerusakan mikrobiologis PM lebih cepat dibandingkan kerusakan secara aktualnya. Hal ini berguna untuk meningkatkan kewaspadaan dan melakukan tindakan pencegahan sebelum kerusakan mikrobiologis PM mencapai batas maksimalnya.

\section{DAFTAR PUSTAKA}

Arini LDD. 2017. Pengaruh pasteurisasi terhadap jumlah koloni bakteri pada susu segar dan UHT sebagai upaya menjaga kesehatan. Indonesian J Med Sci 4: 119-132.

Budiyono H. 2009. Analisis daya simpan produk susu pasteurisasi berdasarkan kualitas bahan baku mutu susu. J Paradigma 10: 198-211.

Ellouze M, Augustin JC. 2010. Applicability of biological time and temperature integrators as quality and safety indicators for meat products. Int $\mathrm{J}$ Food Microbiol 138: 119-129. DOI: 10.1016/j. ijfoodmicro.2009.12.012..

Giannoglou M, Touli A, Platakou E, Tsironi T, Taoukis PS. 2014. Predictive modeling and selection of TTI smart labels for monitoring the quality and shelf-life of frozen seafood. Innov Food Sci Emerg 26: 294-301. DOI: 10.1016/j. ifset.2014.10.008.

Hashempour-Baltork F, Torbati M, AzadmardDamirchi S, Savage GP. 2016. Trends in food science and technology vegetable oil blending: A review of physicochemical, nutritional, and health effects. Tends Food Sci Tech 57: 52-58. DOI: 10.1016/j.tifs.2016.09.007.

Kim J, Kim DN, Lee SH, Yoo SH, Lee S. 2010. Correlation of fatty acid composition of vegetable oils with rheological behaviour and oil uptake. Food Chem 118: 398-402. DOI: 10.1016/j. foodchem.2009.05.011.

Kim JU, Ghafoor K, Ahn J, Shin S, Lee SH, Shahbaz HM, Shin HH, Kim S, Park J. 2015. Kinetic modelling and characterization of a diffusion-based Time Temperature Indicator (TTI) for monitoring microbial quality of non pasteurized angelica juice. LWT-Food Sci Tech 67: 143-150. DOI: 10.1016/j.Iwt.2015.11.034.

Octaviasari R. 2014. Identifikasi indikator dan medium untuk label cerdas pencatat umur simpan produk [Skripsi]. Bogor: Fakultas Teknologi Pertanian, Institut Pertanian Bogor.

Pereira VA, de Arruda INQ, Stefani R. 2015. Active chitosan/PVA films with anthocyanins from Brassica oleraceae (red cabbage) as time-temperature indicators for aplication in intelligent food packaging. Food Hydrocolloid 43: 180188. DOI: 10.1016/j.foodhyd.2014.05.014.

Roiaini M, Ardiannie T, Norhayati H. 2015. Physicochemical properties of canola oil, oilve oil, and palm olein blends. Int Food Res J 22: 12271233.

Rosyidah T. 2005. Aproksimasi fungsi suhu terhadap koefisien difusi pada suatu zat cair [Skripsi]. Jember: Fakultas Keguruan dan IImu Pendidikan, Universitas Jember.

Setiawan J. 2012. Pengembangan program perhitungan koefisien difusi material dalam rekayasa permukaan. Widyariset 15: 551-556.

Suppakul P, Kim DY, Yang JH, Lee SB, Lee SJ. 2017 November. Practical design of a diffusiontype time-temperature indicator with intrinsic low temperature dependency. J Food Eng 223: 22-31. DOI: 10.1016/j.jfoodeng.2017.11.026.

Wang S, Liu X, Yang M, Zhang Y, Xang K, Tang R. 2015. Review of time temperature indicators as quality monitors in food packaging. Packag Technol Sci 28: 839-867. DOI: 10.1002/pts. 2148.

Zhou L, Nyberg K, Rowat AC. 2015. Understanding diffusion theory and Fick's law through food and cooking. Adv Physiol Educ 39: 192-197. DOI: 10.1152/advan.00133.2014. 